\title{
NUMERICAL AND EXPERIMENTAL ANALYSIS OF RESIDUAL STRESSES INDUCED IN METAL COATINGS THERMALLY DEPOSITED (HVOF) ON $\mathrm{Al}_{2} \mathrm{O}_{3}$ SUBSTRATES
}

\author{
JoLANTA ZimMERMAN \\ Warsaw University of Technology, Institute of Mechanics and Printing, Warszawa, Poland \\ e-mail: jolz@wip.pw.edu.pl
}

\begin{abstract}
The study is concerned with the modeling of residual stresses in thin coatings thermally deposited with a high speed on a substrate. The modeling includes two stages: solution of the particle-target impact problem using FEM and simulation of the spraying process with the use of a thermo-mechanical model in which the coating has been built layer-by-layer. The samples used in the calculations are comprised of $\mathrm{Ti}, \mathrm{Cu}$, and $\mathrm{Ni}$ coatings deposited on $\mathrm{Al}_{2} \mathrm{O}_{3}$ substrate by the HVOF method. The numerical model is verified experimentally by measuring the deflections of the samples after spraying, and measuring the stresses using the XRD method.
\end{abstract}

Keywords: metal coatings, $\mathrm{Al}_{2} \mathrm{O}_{3}$ substrate, thermal spraying, FEM simulation, residual stress

\section{Introduction}

Advanced ceramic materials are increasingly used in many industrial branches such as the aircraft, automotive, energy, and chemical industries. The industrial application of ceramics as electric insulators or substrates requires joining them with metals. One of the cheapest methods of joining ceramics with metals is thermal spraying (Chmielewski et al. 2013; Zimmerman et al., 2013; Zimmerman, 2014). The high velocity oxy flame (HVOF) spray is a particle deposition process in which heated micro-size particles are propelled and deposited on a substrate at high speeds to form a thin layer of lamellar coating. The final stress state through the coating/substrate system is determined by superposition of stresses of different nature induced during the spray process: rapid cooling of the softened powder particles after their hitting the substrate and previously deposited sub-layer (quenching stresses), thermal mismatch between the substrate and the coating materials, stresses generated when the particles hit the substrate (peening stresses), and stresses induced during the final cooling of the entire system (Lyphout et al., 2008). The unfavorable distribution of residual stresses in the coating as well as at the coating/substrate interface may adversely affect the service life of the ceramic/metal joint or the operational surface leading even to its delamination during exploitation (Hutchinson and Evans, 2002). Moreover, ceramic materials have low thermal conductivity and poor diffusivity, which constitutes a barrier to the flow of heat. In effect, high temporary temperature gradients may occur in the ceramic material resulting in the generation of thermal stresses and, in consequence, an increase in the risk of micro-cracking (Golanski, 1996).

There is a variety of methods used for estimating the residual stress state induced in the coating/substrate systems, such as experimental methods (Toparli et al., 2007; Lyphout et al., 2008; Luzin et al., 2011), analytical methods (Stokes and Looney, 2003; Tsui and Clyne, 1997; Feng et al., 2007), hybrid methods (Salbut et al., 1999), and numerical models. Analytical methods are usually used for simple systems and do not take into account the plastic behavior of the metal. Some studies devoted to the numerical modeling of the residual 
stress state in coating/substrate systems, often using the finite element method (FEM), considered axisymmetric (Wenzelburger et al., 2004; Kamara and Davey, 2007; Toparli et al., 2007) or plate models (Yilbas and Arif, 2007) with the coating modeled as a single layer and with stresses examined only when the entire system was cooled after the deposition of the coating. In other numerical studies, the growth of the sprayed coating was modeled by activating the successive sub-layers deposited on the substrate ( $\mathrm{Ng}$ and Gan, 2005; Zimmerman et al., 2013; Zimmerman, 2014). Still, other authors concentrate on the modeling of the impacts of individual particles on a metallic substrate (Bansal et al., 2006; Lyphout et al., 2008; Kim et al., 2010) and on the effect of the impact velocity on the microstructure of the coating.

A description of the complex thermal spraying process in physical terms is difficult and the existing numerical models which describe the deposition of the coating and generation of residual stresses, require further improvements. These models take no account of how the magnitude of the final residual stresses depends on the mechanical stresses induced during the high-velocity impact of the coating particles. The present study considers this problem. The objective of this study is to evaluate the final residual stress distributions in the $\mathrm{Ti}, \mathrm{Ni}$, and $\mathrm{Cu}$ coatings deposited on an $\mathrm{Al}_{2} \mathrm{O}_{3}$ substrate by the HVOF method. The results of calculations have been verified by measuring experimentally the central deflections of the samples after they were cooled. The residual stresses have been found by using X-ray diffraction method.

Thin metallic layers formed on an $\mathrm{Al}_{2} \mathrm{O}_{3}$ substrate can serve as the aim of metallizing the ceramic surface or function as a transition layer in joining the ceramic with metals (Chmielewski et al., 2013). They can also play the role of protective coatings against the action of environmental factors such as high temperatures, aggressive environments or mechanical action (Chmielewski and Golański, 2011).

\section{Spraying process}

The experiments include a deposition of titanium, copper, and nickel coatings on an $\mathrm{Al}_{2} \mathrm{O}_{3}$ substrate by the HVOF method using HV-50 system with JP-5000 torch. The process parameters are given in Table 1.

Table 1. The parameters of HVOF thermal spraying applied for coating $\mathrm{Al}_{2} \mathrm{O}_{3}$ ceramic with metals

\begin{tabular}{|c|c|c|c|c|}
\hline Powder & $\begin{array}{c}\text { Oxygen flow } \\
{[\mathrm{l} / \mathrm{h}]}\end{array}$ & $\begin{array}{c}\text { Kerosene flow } \\
{[\mathrm{l} / \mathrm{h}]}\end{array}$ & $\begin{array}{c}\text { Nitrogen flow } \\
{[\mathrm{l} / \mathrm{min}]}\end{array}$ & $\begin{array}{c}\text { Spraying distance } \\
{[\mathrm{mm}]}\end{array}$ \\
\hline \hline $\mathrm{Ni}$ & 849 & 24 & 9.5 & 370 \\
\hline $\mathrm{Cu}$ & 932 & 26.5 & 9.9 & 370 \\
\hline $\mathrm{Ti}$ & 932 & 26.5 & 14 & 370 \\
\hline
\end{tabular}

The starting materials are powders with a grain size between 0.04-0.05 mm. The $\mathrm{Al}_{2} \mathrm{O}_{3}$ substrates are circular plates $27 \mathrm{~mm}$ in diameter and $0.6 \mathrm{~mm}$ thick. The average thickness of the deposited coatings is $t h_{\mathrm{Ti}}=0.12 \mathrm{~mm}, t h_{\mathrm{Ni}}=0.13 \mathrm{~mm}$, and $t h_{\mathrm{Cu}}=0.1 \mathrm{~mm}$. Exemplary photographs of the microstructure of the $\mathrm{Ti}$, and $\mathrm{Cu}$ coatings deposited on the $\mathrm{Al}_{2} \mathrm{O}_{3}$ substrate are shown in Fig. 1a and 1b, respectively. It can be seen that the coatings have a lamellar structure, which is a result of successive depositions of the individual sub-layers on the substrate. The porosity of the coatings is low and they well adhere to the substrate. 
(a)

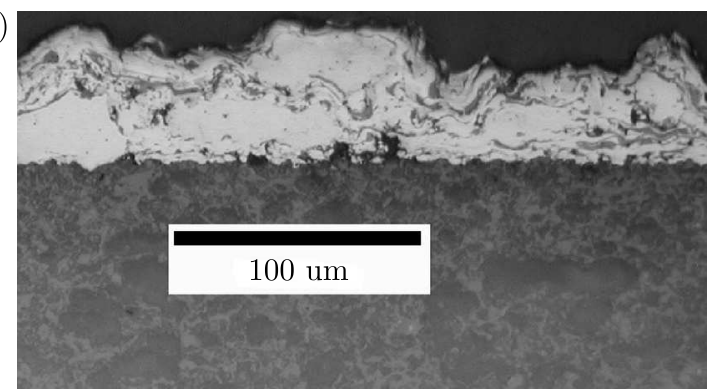

(b)

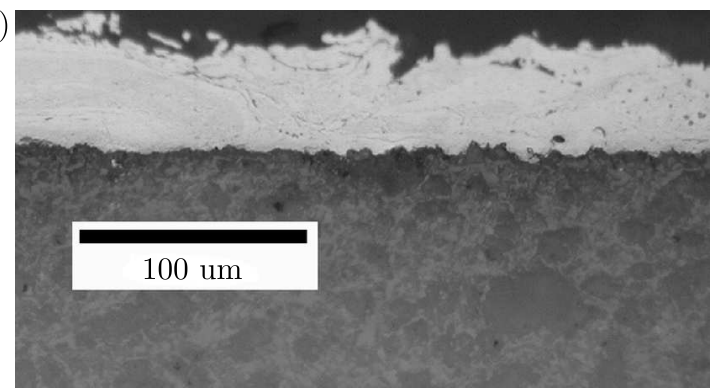

Fig. 1. Microstructure of: (a) the Ti coating (about $60 \mu \mathrm{m}$ thick), (b) the $\mathrm{Cu}$ coating (about $50 \mu \mathrm{m}$ thick) deposited on an $\mathrm{Al}_{2} \mathrm{O}_{3}$ substrate by the $\mathrm{HVOF}$ method

\section{Modeling methods}

In view of the complexity of the spraying process, certain physical simplifications have been assumed in the designing of the numerical model intended for the FE analysis of the residual stresses active in the coating/substrate system. The assumptions underlying the numerical model include:

- The droplet deposition process proceeds in two phases: impact of the particle and its spreading on the substrate. The duration of these two phases is much shorter than that necessary for the droplet to solidify and, thus, the initial spreading phase can be neglected (Amon et al., 1996). This assumption decouples the problem from the fluid dynamics and permits it to be simplified to a thermo-mechanical problem. The time interval when the particles are in the impact, heating, and cooling phases is shorter by at least two orders of magnitude than the duration of the spraying cycle (Watanabe et al., 1992). In effect, the next particles impinge on the previously deposited sub-layer when it is already solidified. The substrate and the earlier deposited sub-layers are modeled as being in the solid state with a defined temperature field, and their mechanical and physical properties depend on temperature.

- The high-velocity impact of the particles onto the substrate results in their substantial deformation and transforms $70 \%$ of their kinetic energy into heat energy. The particles are flattened and arranged approximately in a parallel layer structure, and during the successive passes of the torch, new particles are deposited on them.

- The contact between the substrate and the subsequently deposited sub-layers is ideal so as there are no thermal barriers between them.

The modeling of the residual stresses generated during the spraying process is divided into two stages. In the first stage the problem of the dynamic impact of spherical powder particles on the substrate is solved using FEM ADINA 8.6 software in the explicit dynamics mode. In the next modeling stage, the coating is built of successively grown 'discs' at time intervals defined by the spraying process parameters until the coating achieved the required thickness and, then, the entire coating/substrate system is cooled to room temperature. This problem is solved using ADINA 8.6 software in the thermo-mechanical mode. The flow chart of modeling the residual stresses induced in the coatings thermally sprayed on the substrate is shown in Fig. 2. As can be seen, the data calculated in the initial stage concerning the dynamic impact of the particle on the substrate, such as temperature, and the vertical deceleration of the particle are introduced at the appropriate calculation stages into the thermal and mechanical models.

During the coupled analysis, the coating is built step-by-step to the desired thickness, which is accompanied by the development of residual stresses in the coating/substrate system. 
Explicit analysis

Thermal analysis

Stress analysis

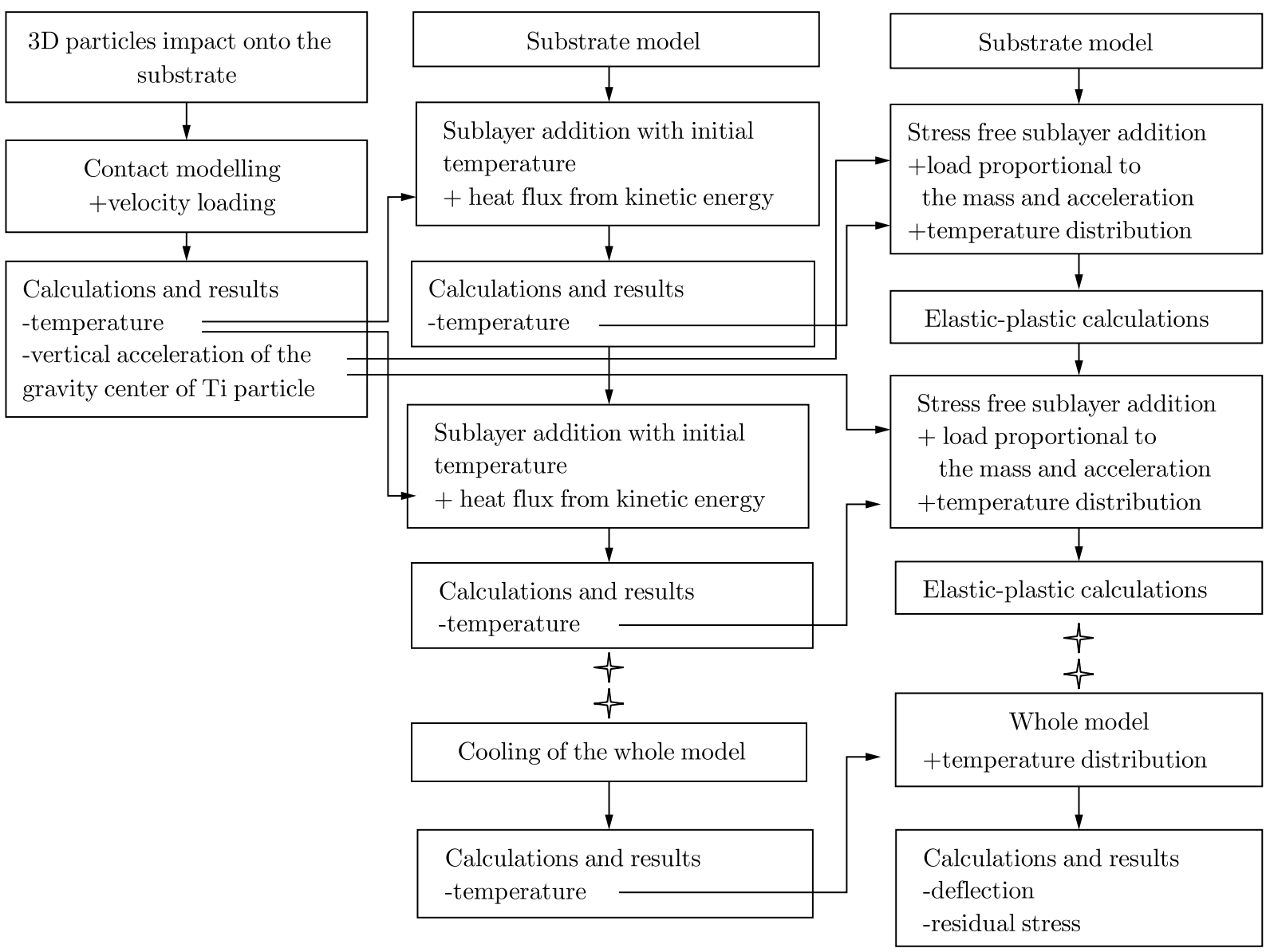

Fig. 2. Flow chart of the FEM simulation used for determining the residual stress distribution in HVOF-sprayed coatings

\subsection{The particle impact model and calculation results}

Despite their small masses, the particles hitting the substrate with a high velocity deform, to some extent, the previously deposited sub-layers, which generates a stress field and has a significant effect on the final residual stress state (Bansal et al., 2006; Toparli et al., 2007; Lyphout et al., 2008). Therefore, the present study is focused on the modeling of the particle impact. Li et al. (2006) showed that during thermal spraying by the industrial HVOF method, the individual powder particles can be considered to be separated from one another and they do not coagulate during their flight. The spatial (3D) model used in the present study has been developed to simulate the deformation and changes in the velocity and acceleration of the individual spherical particles of the coating powder, which impinge on the substrate. During the deformation, the particles block one another forming thereby a flat splat almost parallel to the substrate. In the modeling of the dynamics of the particle motion, it is assumed for simplicity that the particles have the same velocity perpendicular to the substrate and, when hitting the substrate, they form a hexagonal configuration which ensures their most tight packing. The contact planes are situated in the model to block the successive rows of particles. The model utilized the planes of symmetry, which permitted reducing the size of the problem. A schematic representation of the section geometry together with the displacement-blocking planes and the entire FEM mesh are shown in Fig. 3. The numerical calculations have been made using ADINA 8.6 FEM software in the dynamics-explicit analysis mode. The impact velocity of the particles was $600 \mathrm{~m} / \mathrm{s}$ as 
estimated based on the process parameters and calculations reported by Li et al. (2006) for the powder with the particle diameter $d=40-50 \mu \mathrm{m}$.
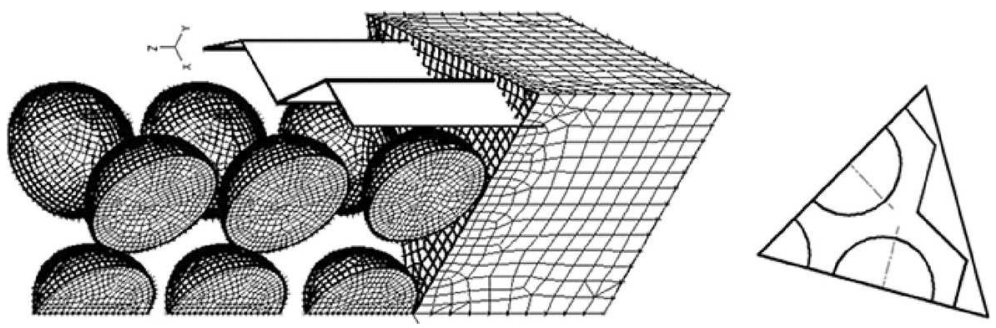

Fig. 3. Geometry and the final element mesh of the model representing the particles impact onto a substrate

Some exemplary calculation results obtained for Ti particles, which impinge on a ceramic substrate, are presented. The properties of titanium are taken to be those valid at a temperature of $300^{\circ} \mathrm{C}$, and the elastic-plastic model of the material with the Young modulus $123800 \mathrm{MPa}$, yield stress $233 \mathrm{MPa}$, hardening modulus $600 \mathrm{MPa}$, and the specific gravity $4.54 \mathrm{~g} / \mathrm{cm}^{3}$. The ceramic substrate is modeled as an elastic material with the specific gravity $3.9 \mathrm{~g} / \mathrm{cm}^{3}$ and the Young modulus $318200 \mathrm{MPa}$. The model assumes that the particles are in contact with one another, with the substrate and with the blocking planes (40 contact pairs in total). The thickened mesh lines indicate the contact surfaces in Fig. 3.

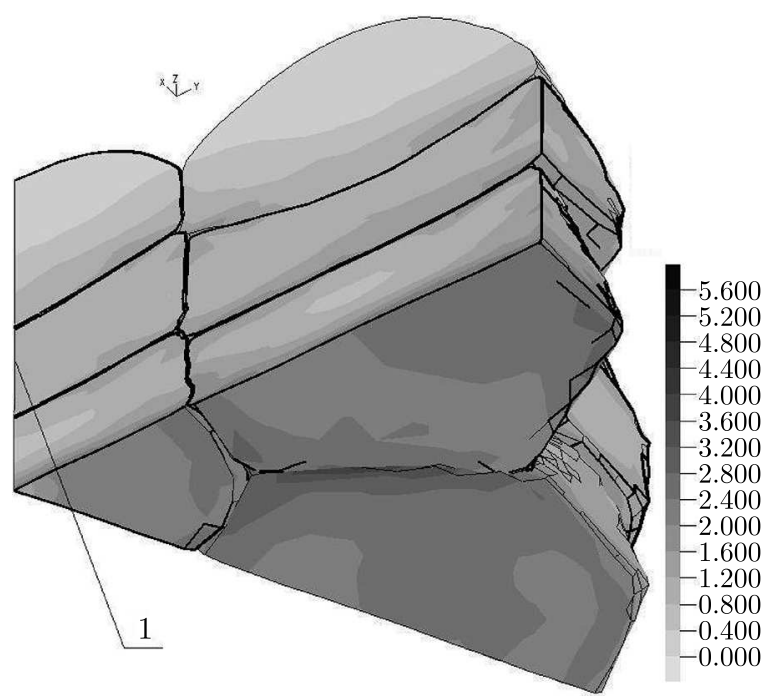

Fig. 4. Bands of the equivalent plastic strains in the titanium particles after their impact

Figure 4 shows the distribution of plastic deformations of Ti particles (which after impinging on the $\mathrm{Al}_{2} \mathrm{O}_{3}$ substrate form a sub-layer of the coating) after a time of $70 \mathrm{~ns}$ when their velocity decreased to zero. The maximum strains of $500 \%$ are located near the stiffer substrate and near the contact zone. The particles are flattened, come in contact with one another and fill the free spaces between them. The analysis reveals that after the impact of a particle $50 \mu \mathrm{m}$ in diameter, the already-deposited particles which are in immediate contact with the substrate change their shapes into discs with a diameter of $12 \mu \mathrm{m}$. Figures $5 \mathrm{a}$ and $5 \mathrm{~b}$ show the changes of the velocity and acceleration, respectively, of the center of mass of the Ti particle (' 1 ' indicated in the Fig. 4) after its impact on the substrate. The plot of acceleration of the particle mass center, proportional to the derivative of the momentum, is obtained by double numerical differentiation of time-variation of the displacement. Upon the impact of a particle onto the $\mathrm{Al}_{2} \mathrm{O}_{3}$ substrate, its acceleration reaches a value of about $-36000 \mu \mathrm{m} / \mathrm{s}^{2}$. The oscillations of the particle acceleration visible in 
Fig. 5b are due to inhomogeneity of the deformation and vibrations induced by the high-velocity impact of the particle on the substrate accompanied by phenomena wavy in character.
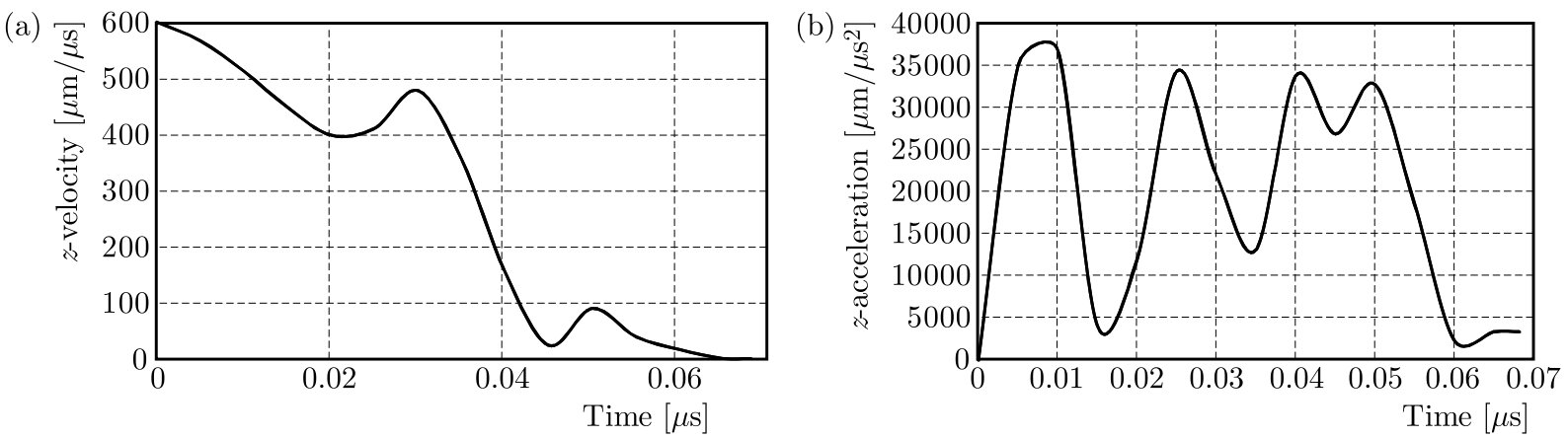

Fig. 5. FEM-calculated (a) velocity, (b) acceleration of the mass center of the centrally-positioned Ti particle after its impact onto the $\mathrm{Al}_{2} \mathrm{O}_{3}$ substrate

\subsection{Thermo-mechanical model}

The thermal spraying process is simulated using an axisymmetric model. The modeling is divided into several stages and the calculations conducted during each stage are based on the equations of transient heat flow. The layer deposition interval is taken to be $1 \mathrm{~s}$ and has been estimated from the torch movements during the spraying process. The real coating is built of five sub-layers.

The boundary and initial conditions adopted in the thermal model are as follows. The heat exchange between the HVOF stream of the torch and the newly-deposited top sublayers of the coating proceeds through convection. The convection coefficient is taken to be $h_{b}=100 \mathrm{Wm}^{-2} \mathrm{~K}^{-1}$ (Toparli et al., 2007) and the air temperature from the side of the approaching particles to be $T_{b}=150^{\circ} \mathrm{C}$. The heat exchange between the bottom side of the substrate and the ambience proceeds through convection with the convection coefficient $h_{a}=10 \mathrm{Wm}^{-2} \mathrm{~K}^{-1}$. The ambient temperature is assumed to be $T_{a}=25^{\circ} \mathrm{C}$. The initial temperature of the individual coating sub-layers are for titanium $T_{\text {init-Ti }}=450^{\circ} \mathrm{C}$ ( $\mathrm{Kim}$ et al., 2010), for nickel $T_{\text {init-Ni }}=400^{\circ} \mathrm{C}$, and for copper $T_{\text {init }-\mathrm{Cu}}=350^{\circ} \mathrm{C}$. The interfaces between the substrate and the first-deposited sub-layer as well as between successive sub-layers are loaded with the heat flux $q$ which acts for $t_{q}=1 \mu \mathrm{s}$ and is activated upon the appearance of the next new sub-layer. The heat flux is assumed to be such that it corresponds to the transformation of kinetic energy into heat energy at a spraying speed of $600 \mathrm{~m} / \mathrm{s}$. After achieving the required thickness of the coating, the entire system is cooled down to room temperature. Figure 6a shows a schematic physical and thermo-mechanical description of the HVOF process.

The problem of the temperature field induced in the thermally sprayed coatings has been solved using ADINA 8.6 FE thermal module. The mesh consists of 25480 4-node conducting elements for the substrate and coating materials, and 3640 2-node convection elements at the edges. The finest mesh has been introduced to each layer of the metal coating. The conductive elements of the newly deposited sub-layer and the convection elements of its upper surface are activated at the time intervals $t=1 \mathrm{~s}$, while at the same time, the convection elements in-between sub-layers are deactivated. Hence, the temperature field induced in the spraying process is the problem with a moving boundary condition in which the outer surface of the coating grows at the time intervals dependent on the spraying frequency. Figure $6 \mathrm{~b}$ presents a fragment of the mesh of the layer-by-layer model indicating the initial and boundary conditions upon the activation of the 5-th sub-layer.

The stress analysis (mechanical model) included a comparison between the results obtained for two different loads applied to the model. In the first case (FEM1), the load is assumed to 

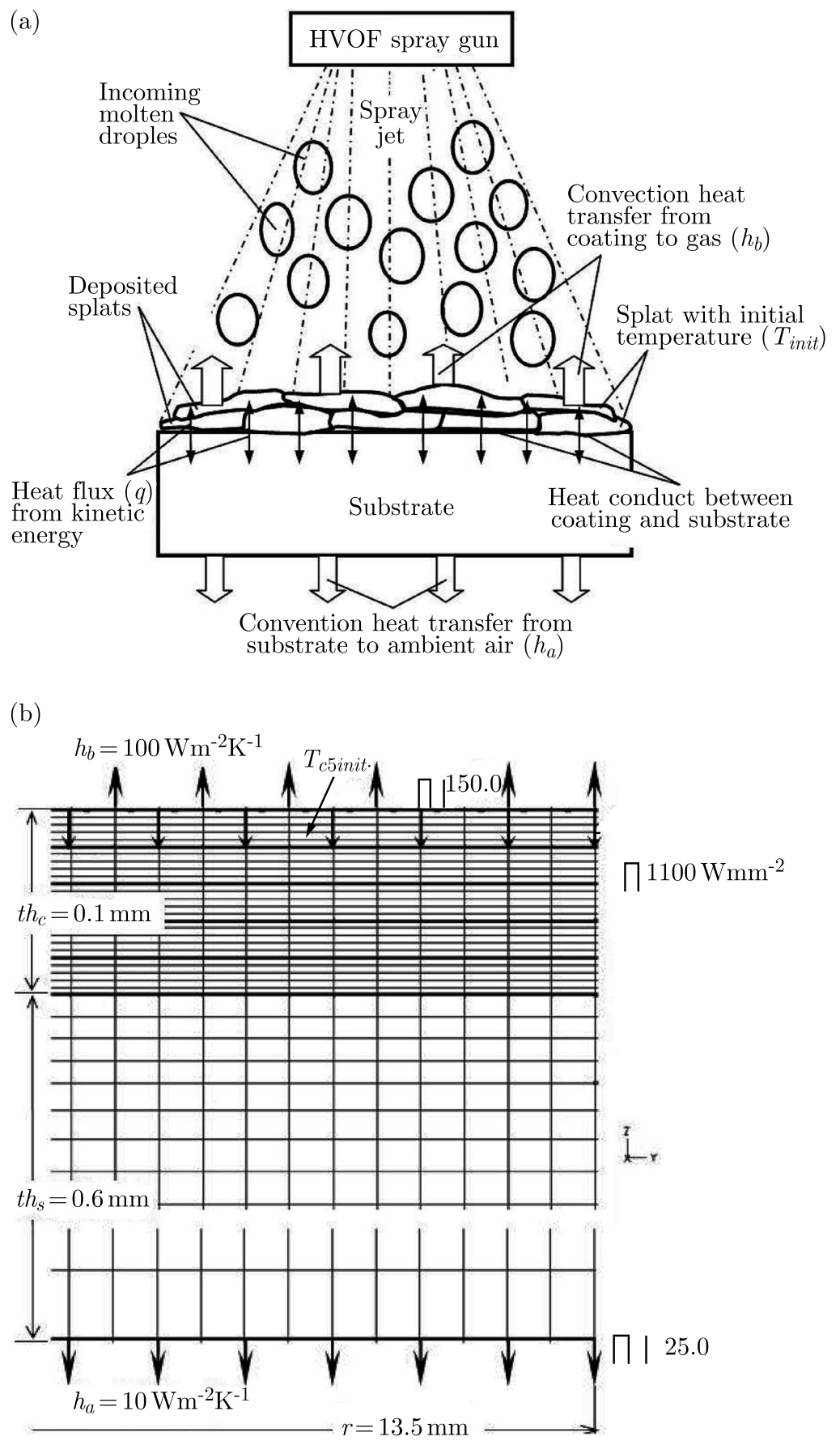

Fig. 6. Schematic physical and thermo-mechanical description of the HVOF process (a), part of the FEM mesh of the layer-by-layer model with the boundary conditions upon the activation of the 5-th sub-layer (b)

be the temperature field obtained in the solution of the problem of transient heat flow during the successive time increments in which current and stress-free sub-layers onto the initially stressed system have been added. In the other case (FEM2), the temperature field is added with a load (active for $0.1 \mu \mathrm{s}$ ) proportional to the mass and acceleration of each newly incoming sub-layer. The acceleration is estimated based on the time variation of the displacement of the center of mass of the centrally-positioned particle (point 1 indicated in Fig. 4), a diagram of which has been obtained from the solution to the particle impact dynamic problem. This approach enables taking into account the influence of the impact of coating particles on the 
substrate and the earlier-deposited sub-layer on the final residual stress state. The magnitudes of particle impact pressure are assumed to be $170 \mathrm{MPa}, 200 \mathrm{MPa}$ and $300 \mathrm{MPa}$ for systems with $\mathrm{Ni}, \mathrm{Cu}$ and Ti coatings, respectively. In the modeling, it is assumed that behavior of the ceramic substrate is elastic, whereas the metallic materials are described by the elastic-plastic model. The temperature-dependent properties (specific heat capacity, thermal conductivity, Young's modulus, yield strength, hardening modulus, thermal expansion coefficient) for $\mathrm{Ti}, \mathrm{Ni}$, and $\mathrm{Cu}$ coatings and the $\mathrm{Al}_{2} \mathrm{O}_{3}$ substrate are presented in Table 2 based on data taken after Boyer et al. (1994), Dobrzanski (2002), Dorf (2004) and Goldsmith et al. (1961).

Table 2. Material properties of the substrate and coatings

\begin{tabular}{|l|c|c|c|c|c|c|c|c|c|c|}
\hline & \multicolumn{5}{|c|}{$\mathrm{Ti}$} & \multicolumn{5}{|c|}{$\mathrm{Al}_{2} \mathrm{O}_{3}$ (substrate) } \\
\hline \hline$T\left[{ }^{\circ} \mathrm{C}\right]$ & 27 & 127 & 227 & 327 & 427 & 27 & 127 & 227 & 327 & 427 \\
\hline$C\left[\mathrm{Jkg}^{-1} \mathrm{~K}^{-1}\right]$ & 523 & 546 & 561 & 597 & 632 & 754 & 951 & 1005 & 1089 & 1130 \\
\hline$k\left[\mathrm{Wm}^{-1} \mathrm{~K}^{-1}\right]$ & 21.9 & 21.0 & 20.4 & 19.7 & 19.4 & 34.6 & 25.1 & 19.0 & 14.7 & 11.2 \\
\hline$E[\mathrm{GPa}]$ & 130 & 129 & 127 & 124 & 120 & 318.3 & 317 & 315 & 313 & 310 \\
\hline$Y[\mathrm{MPa}]$ & 380 & 285 & 250 & 205 & 170 & \multicolumn{3}{|c|}{ not considered (elastic model) } \\
\hline$E_{t}[\mathrm{MPa}]$ & 880 & 760 & 640 & 600 & 580 & \multicolumn{1}{|c|}{ not considered (elastic model) } \\
\hline$\alpha\left[10^{-6} \mathrm{~K}^{-1}\right]$ & 8.4 & 8.7 & 9.1 & 9.4 & 9.7 & 5.9 & 6.5 & 7.1 & 7.6 & 8.0 \\
\hline & \multicolumn{9}{|c|}{ Ni } & \multicolumn{6}{|c|}{$\mathrm{Cu}$} & \\
\hline \hline$T\left[{ }^{\circ} \mathrm{C}\right]$ & 27 & 127 & 227 & 327 & 427 & 27 & 127 & 227 & 327 & 427 \\
\hline$C\left[\mathrm{Jkg}{ }^{-1} \mathrm{~K}^{-1}\right]$ & 462 & 505 & 554 & 599 & 526 & 385 & 398 & 408 & 417 & 425 \\
\hline$k\left[\mathrm{Wm}{ }^{-1} \mathrm{~K}^{-1}\right]$ & 90.5 & 80.1 & 72.1 & 65.5 & 65.3 & 398 & 392 & 388 & 383 & 377 \\
\hline$E[\mathrm{GPa}]$ & 208 & 204 & 197 & 190 & 183 & 130 & 128 & 124 & 119 & 112 \\
\hline$Y[\mathrm{MPa}]$ & 150 & 157 & 145 & 143 & 120 & 210 & 205 & 195 & 140 & 85 \\
\hline$E_{t}[\mathrm{MPa}]$ & 670 & 660 & 690 & 670 & 340 & 250 & 230 & 200 & 150 & 100 \\
\hline$\alpha\left[10^{-6} \mathrm{~K}^{-1}\right]$ & 13.9 & 14.4 & 14.9 & 15.5 & 16.0 & 15.4 & 15.9 & 16.6 & 17.1 & 18.5 \\
\hline
\end{tabular}

$C$ - specific heat, $k$ - thermal conductivity, $\alpha-$ CTE

$E$ - Young's modulus, $Y$ - yield strength, $E_{t}-$ hardening modulus

\section{Measurements of residual stresses}

The samples, i.e. $\mathrm{Al}_{2} \mathrm{O}_{3}$ substrates with $\mathrm{Ti}, \mathrm{Ni}$, and $\mathrm{Cu}$ coatings, are deflected in various ways after thermal spraying. Their deflections are measured using a specially designed device with a digital dial gauge. The measurement is conducted at the center of the sample on the substrate side. The indication of the dial gauge has been calibrated to zero for each ceramic substrate before the deposition. Table 3 compares the deflections of the samples at their center between those measured and those calculated by FEM. The results appear to be in agreement within the limits of admissible error in case FEM2.

Table 3. The measured and calculated by FEM central deflection of analyzed samples

\begin{tabular}{|c|c|c|c|c|}
\hline \multirow{2}{*}{ Coating } & Mean coating & \multicolumn{3}{|c|}{ Sample deflection [mm] } \\
\cline { 3 - 5 } & thickness [mm] & measured & calculated FEM1 & calculated FEM2 \\
\hline \hline $\mathrm{Ti}$ & 0.119 & $0.064 \pm 0.018$ & 0.078 & 0.066 \\
\hline $\mathrm{Ni}$ & 0.133 & $0.069 \pm 0.011$ & 0.073 & 0.062 \\
\hline $\mathrm{Cu}$ & 0.105 & $0.060 \pm 0.023$ & 0.061 & 0.049 \\
\hline
\end{tabular}

The stresses generated in the sprayed coatings, are also estimated by the X-ray method using filtered CoK $\alpha$ radiation $(\lambda=1.79026)$. The measurement of the residual stresses has been 
preceded by the X-ray phase analysis. All the measurements have been made using a Brucker D8 Discover diffractometer equipped with a Lynx Eye position-sensitive detector with the $2.6^{\circ}$ angular detection range and a Poly Cup primary beam-measuring optics with a pinhole-type collimator and an aperture of $1.0 \mathrm{~mm}$.

The stress characteristics are determined in the sub-surface layer at a small depth (to about $20 \mu \mathrm{m}$ ) in a region with the surface area of about $2 \mathrm{~mm}^{2}$ located in the center of the sample. The stresses are measured in the plane of the coating. The values of the principal stresses active in the coating plane (determined by the $\sin ^{2} \varphi$ method) are given in Table 4 .

Table 4. The magnitude of principal stresses in sprayed coatings obtained by the X-ray diffraction method

\begin{tabular}{|c|c|c|}
\hline \multirow{2}{*}{ Coating } & \multicolumn{2}{|c|}{ Principal stress [MPa] } \\
\cline { 2 - 3 } & $\sigma_{1}$ & $\sigma_{2}$ \\
\hline \hline $\mathrm{Ti}$ & $192.0 \pm 55.0$ & $350.0 \pm 60.0$ \\
\hline $\mathrm{Ni}$ & $84.0 \pm 5.0$ & $93.0 \pm 6.0$ \\
\hline $\mathrm{Cu}$ & $109.0 \pm 7.0$ & $87.0 \pm 9.0$ \\
\hline
\end{tabular}

\section{Calculation results}

Figure 7 shows temperature distributions calculated for the time intervals in which the $\mathrm{Ti}, \mathrm{Ni}$ and $\mathrm{Cu}$ coating are deposited on the ceramic substrate. We can see that temperature of the successive sub-layers rapidly decreases while the substrate is slowly heated up.

(a)

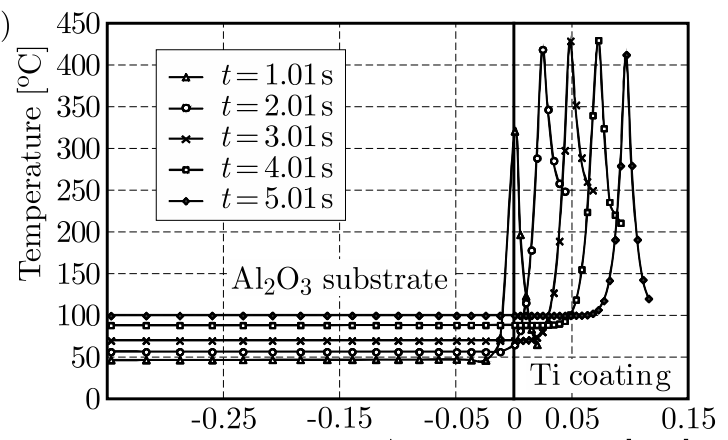

Distance from coating/surface interface $[\mathrm{mm}]$ (b)

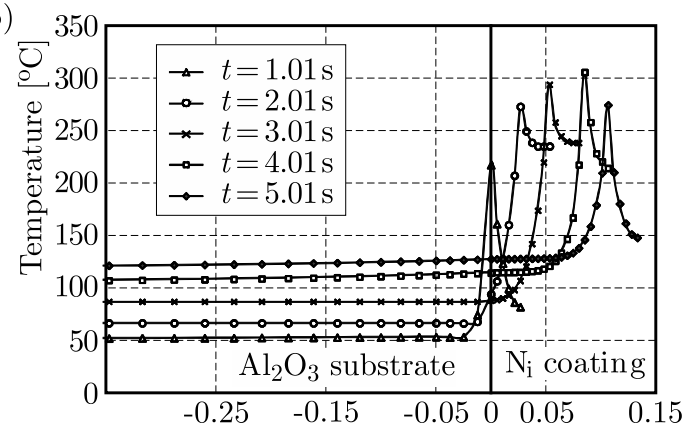

Distance from coating/surface interface $[\mathrm{mm}]$

(c)

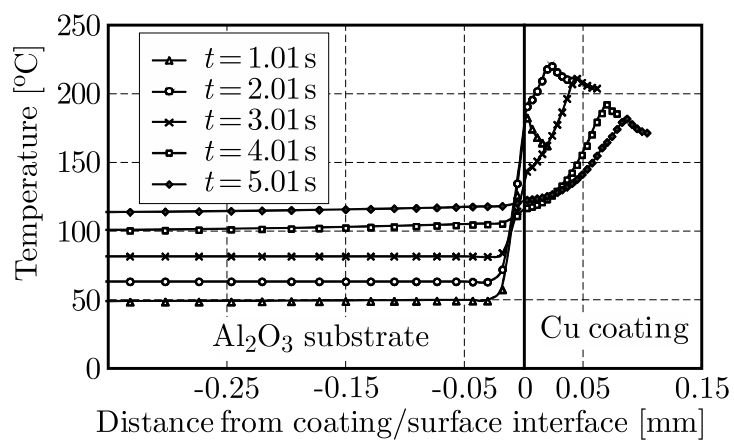

Fig. 7. FEM-calculated temperature distribution along the vertical axis of $\mathrm{Ti}$ (a), Ni (b), Cu (c) coating/substrate system versus the distance from the ceramic/metal interface during the successive time intervals of sub-layer activation

The calculated (using FEM1 and FEM2 models) and measured distributions of the radial residual stresses active in the $\mathrm{Ti} / \mathrm{Al}_{2} \mathrm{O}_{3}, \mathrm{Cu} / \mathrm{Al}_{2} \mathrm{O}_{3}$, and $\mathrm{Ni} / \mathrm{Al}_{2} \mathrm{O}_{3}$ systems as a function of the 
distance from the coating/substrate interface are shown in Figs. 8a, 8b, 8c, respectively. The figures also show the magnitudes of stresses measured by the X-ray method.
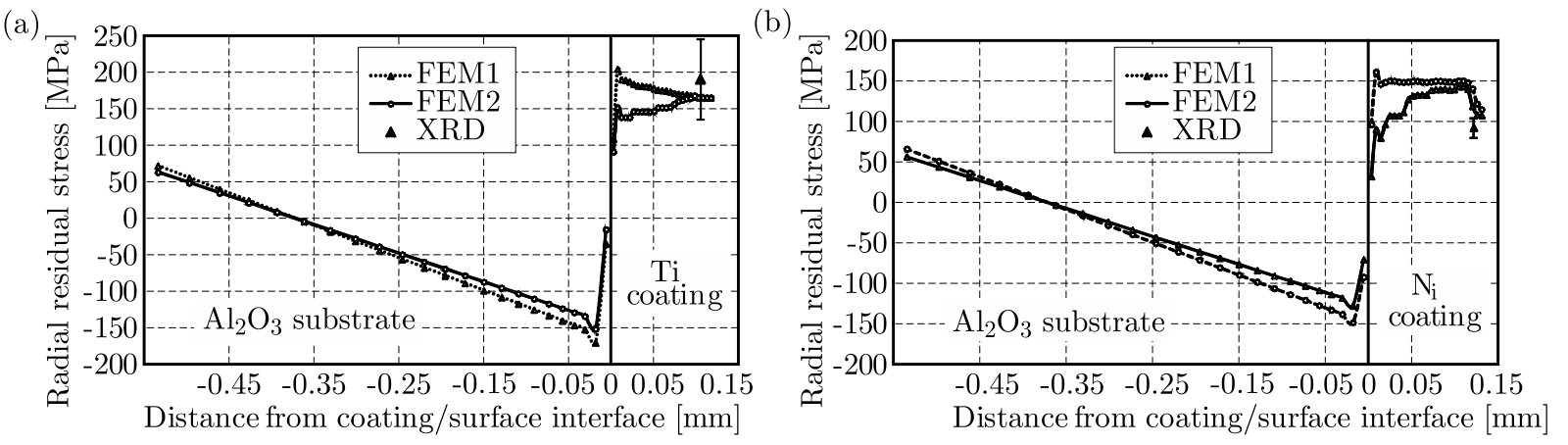

(c)

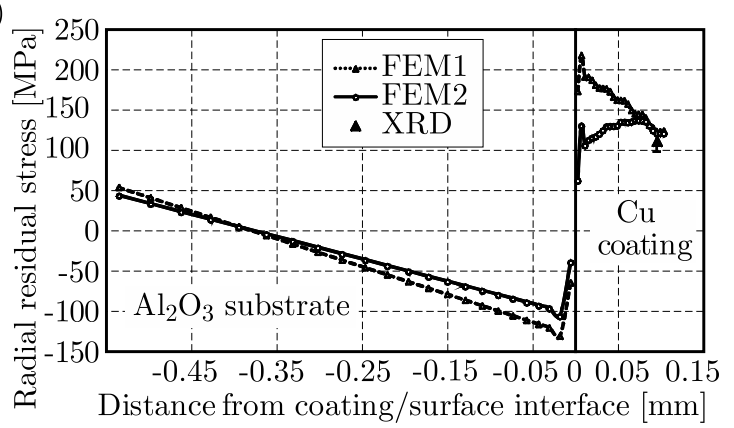

Fig. 8. Radial residual stress profiles along the sample axis as a function of the distance from the $\mathrm{Ti} / \mathrm{AlO} 3$ (a), $\mathrm{Ni} / \mathrm{AlO}_{3}$ (b), $\mathrm{Cu} / \mathrm{AlO}_{3}$ (c) interface

As expected, the stresses induced in the metallic coatings are tensile, since the thermal contraction of a given sub-layer is limited by the cold substrate and the earlier-deposited sub-layers that are in contact with it. In the ceramic substrate, the radial stresses are compressive in the vicinity of the coating/substrate interface and, then, as the distance from it increases, they change into tensile.

In the model assuming the load in form of a temperature field and particle high-velocity impact onto the substrate (FEM2), the magnitude of the residual stresses is lower, especially in the region of the interface, than that in the model loaded with the temperature field only (FEM1). Additional loading in model FEM2 derived from the particle impact results in higher plastic deformation of metal coatings and lower residual stress amplitude at the coating/substrate interface. The zone of plastic deformation is wider in the case of $\mathrm{Ti}$ and $\mathrm{Cu}$ coatings. The plastic deformation is responsible for partial redistribution of stress and decreases the deflection of the overall system. The graph in Fig. 9 shows a change in the effective plastic strains along thickness of $\mathrm{Ti}, \mathrm{Ni}$ and $\mathrm{Cu}$ coatings for both FEM1 and FEM2 models. The plastic deformation reaches maximum in the region around the coating/substrate interface.

\section{Summary and conclusions}

Distributions of the residual stresses active in $\mathrm{Ti}, \mathrm{Cu}$, and $\mathrm{Ni}$ coatings deposited on $\mathrm{Al}_{2} \mathrm{O}_{3}$ substrates by the HVOF method are examined. The stress distributions are simulated using a developed numerical model of coating/substrate system based on the finite element method (FEM). The coatings are modeled as growing layer-by-layer during time intervals defined by spraying procedures. The calculations are performed for two different loads imposed on the mechanical coating/substrate model. In the first case, the model is loaded with a temperature field only and, in the other case, the temperature field is added with a load (acting for $0.1 \mu \mathrm{s}$ ) 
(a)

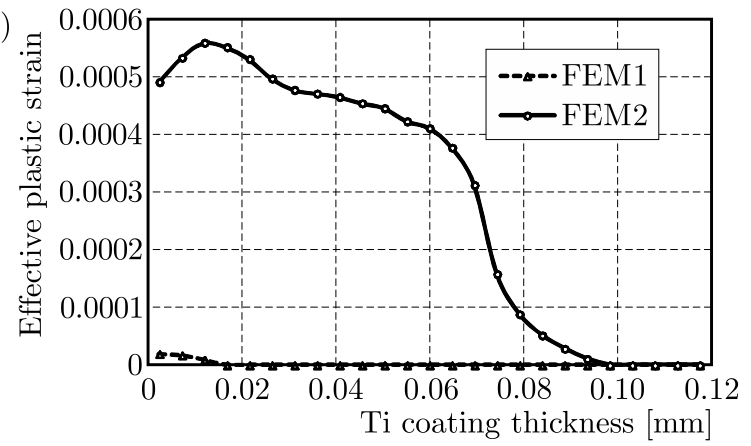

(b)

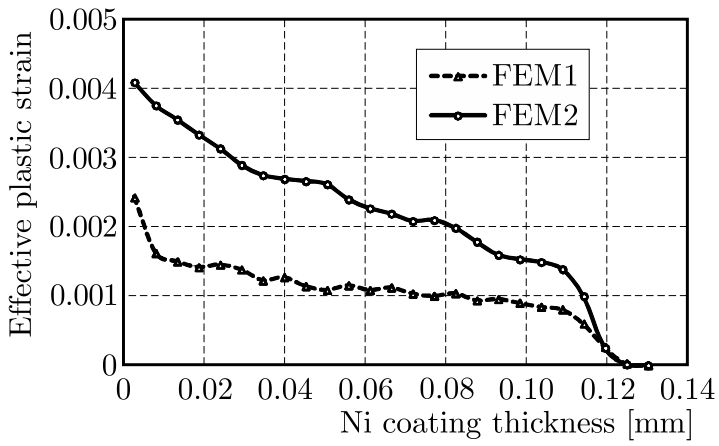

(c)

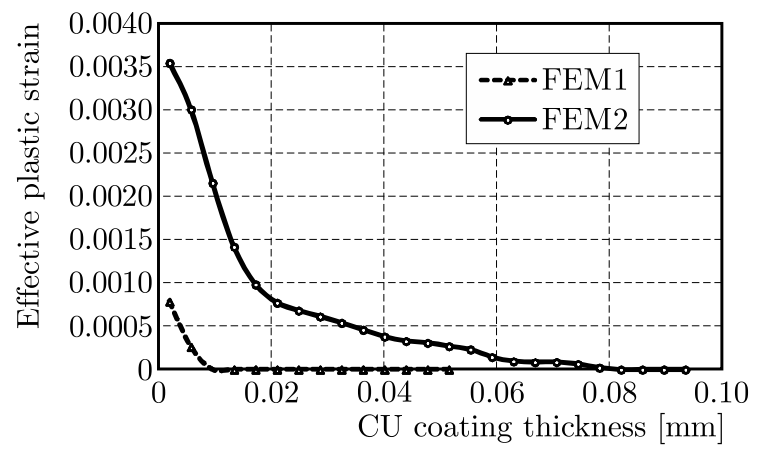

Fig. 9. FEM1, FEM2-calculated effective plastic strain profiles as a function of the Ti (a), Ni (b), Cu (c) coating thickness

proportional to the mass and acceleration of each newly-deposited sub-layer. The acceleration is estimated from the time-variation of the displacement of the center of mass of the centrally-positioned spherical coating particle, which is obtained in the solution to the dynamic particle impact problem. This enables taking into account the effect of high-velocity impact of a coating particle on the final magnitude of residual stresses in the coating/substrate system. The main results can be summarized as follows:

- The deflection of the coating/substrate system simulated using the model loaded with the temperature field and particle impact energy (FEM2) is smaller, and the stresses induced in the vicinity of the coating/substrate interface are lower compared to those simulated in the model loaded by the temperature field only (FEM1).

- The radial stresses active in the ceramic substrate near the coating/substrate interface are compressive and those near the $\mathrm{Ti}, \mathrm{Cu}$, and $\mathrm{Ni}$ coatings are tensile. The FEM model with additional particle impact loading (FEM2) results in a lower residual stress amplitude at the coating/substrate interface.

- The measured deflections of the real samples are in agreement, within the limits of tolerances, with the deflections calculated using the numerical analysis (FEM2).

- In constructing metal/ceramic joints, it is advantageous to use metals with a lower yield stress $\left(\operatorname{Re}_{\mathrm{Ni}}=140 \mathrm{MPa}, \mathrm{Re}_{\mathrm{Cu}}=240 \mathrm{MPa}, \mathrm{Re}_{\mathrm{Ti}}=380 \mathrm{MPa}\right)$ since then redistribution of stresses is greater and, thereby, the residual stress level in the system is lower. In the Ti and $\mathrm{Cu}$ coatings, the stress magnitudes determined at a depth of about $20 \mu \mathrm{m}$ by X-ray diffraction are in agreement with their FEM2-calculated values (within the measurement error), whereas in the $\mathrm{Ni}$ coatings they are lower by about $12 \%$.

- The X-ray analysis used in the present study gives satisfactory results when measuring stresses at very small depths. In order to verify the proposed model, the stresses induced near the coating/substrate interface should be more thoroughly measured by other methods. 
Acknowledgments

This work has been supported by the National Science Centre under project No. N N519 652840.

\section{References}

1. Amon C.H., Merz R., Prinz F.B., Schmaltz K.S., 1996, Numerical and experimental investigation of interface bonding via substrate melting of an impinging molten metal droplet, Journal of Heat Transfer, 118, 164-172

2. Bansal P., Shipway P.H., Leen S.B., 2006, Effect of particle impact on residual stress development in HVOF sprayed coatings, Journal of Thermal Spray Technology, 15, 4, 570-575

3. Boyer R., Welsch G., Collings E., 1994, Materials Property Handbook: Titanium Alloys, ASM International, Materials Park, $\mathrm{OH}$

4. Chmielewski T., Golański D., 2011, New method of in-situ fabrication of protective coatings based on Fe-Al intermetallic compounds, Proceedings of the Institution of Mechanical Engineers, Journal of Engineering Manufacture, Part B, 225 (B4), 611-616

5. Chmielewski T., Golański D., WŁosiński W., 2013, Characterization of thermally sprayed titanium coatings on alumina substrate, [In:] Mechanics and Materials, S. Jemioło, M. Lutomirska (edit.), Publishing House of Warsaw University of Technology, 173-192

6. Dobrzański L.A., 2002, Podstawy nauki o materiałach i metaloznawstwo. Materiały inżynierskie z podstawami projektowania materiałowego, WNT

7. Dorf R.C. (ED.), 2004, Handbook of Engineering Tables, CRC Press LLC

8. Feng X., Huang Y., Rosakis A.J., 2007, On the Stoney formula for a thin film/substrate system with nonuniform substrate thickness, Transactions of the ASME, 74, 1276-1281

9. Golanski D., 1996, Temperature distribution in a cylindrical $\mathrm{Al}_{2} \mathrm{O}_{3}$-steel joint during the vacuum brazing cycle, Journal of Materials Processing Technology, 56, 1/4, 945-954

10. Goldsmith A., Waterman T.E., Hirchorn H.J., 1961, Handbook of Thermophysical Properties of Solid Materials, New York

11. Hutchinson J.W., Evans A.G., 2002, On the delamination of thermal barrier coatings in a thermal gradient, Surface and Coatings Technology, 149, 179-184

12. Kamara A.M., Davey K., 2007, A numerical and experimental investigation into residual stress in thermally sprayed coatings, Solid and Structures, 44, 8532-8555

13. Kim K., Kuroda S., Watanabe M., 2010, Microstructural development and deposition behavior of titanium powder particles in warm spraying process: from single splat to coating, Journal of Thermal Spray Technology, 19, 6, 1244-1254

14. Li M., Panagiotis D., Christofides P., 2006, Computational study of in-flight behavior in the HVOF thermal spray process, Chemical Engineering Science, 61, 6540-6552

15. LuZin V., Spencer K., Zhang M.-X., 2011, Residual stress and thermo-mechanical properties of cold spray metal coatings, Acta Materialia, 59, 1259-1270

16. Lyphout C., Nyle'n P., Manescu A., Pirling T., 2008, Residual stresses distribution through thick HVOF sprayed Inconel 718 coatings, Journal of Thermal Spray Technology, 17, 5/6, 915-923

17. NG H.W., GAN Z., 2005, A finite element analysis technique for predicting as-sprayed residual stress generated by plasma spray coating process, Finite Elements in Analysis and Design, 41, $1235-1254$

18. Salbut L., Kujawinska M., Jozwik M., Golanski D., 1999, Investigation of ceramic-to-metal joint properties by hybrid moire interferometry/FEM analysis, Interferometry'99: Applications. Book Series: Proceedings of The Society of Photo-Optical Instrumentation engineers (SPIE), Juptner W.P.O, Patorski K. (edit.), 3745, 298-306 
19. Stokes J., Looney L., 2003, Residual stress in HVOF thermally sprayed thick deposits, ICMCTF

20. Toparli M., Sen F., Culha O., Celik E., 2007, Thermal stress analysis of HVOF sprayed WC-Co/NiAl multilayer coatings on stainless steel substrate using finite elements methods, Journal of Materials Processing Technology, 190, 23-32

21. Tsui Y.C., Clyne T.W., 1997, An analytical model for predicting residual stresses in progressively deposited coatings. Part 1: Planar geometry, Thin Solid Films, 306, 23-33

22. Watanabe T., Kuribayashi I., Honda T., Kanzawa A., 1992, Deformation and solidification of a droplet on a cold substrate, Chemical Engineering. Science A, 47, 3059-3065

23. Wenzelburger M., Escribano M., Gadow R., 2004, Modeling of thermally sprayed coatings on light metal substrates: layer growth and residual stress formation, Surface and Coatings Technology, 180-181, 429-435

24. Yilbas B.S., ArIF A.F.M., 2007, Residual stress analysis for diamalloy 1005 coating 0n Ti-6Al-4V alloy, Surface and coating Technology, 202, 559-568

25. Zimmerman J., 2014, Finite element modelling of the residual stresses induced in thermally deposited coating, Archives of Metallurgy and Materials, 59, 2, 603-609

26. Zimmerman J., Lindemann Z., Golański D., Chmielewski T., Wlosinski W., 2013, Modeling of the residual stresses generated in thermally sprayed Ti coatings on $\mathrm{Al}_{2} \mathrm{O}_{3}$ substrate, Bulletin of the Polish Academy of Science Technical Sciences, 61, 515-525

Manuscript received December 12, 2014; accepted for print December 18, 2015 